\title{
Análise de parâmetro normatizado para projeto de estruturas de madeira considerando a confiabilidade estrutural
}

\author{
Analysis of a standardized parameter for the design of \\ wooden structures considering structural reliability
}

\author{
Rafael Barreto Castelo da Cruz \\ Luciano Ferreira dos Santos \\ Nilson Tadeu Mascia \\ Maria Cecilia Amorim Teixeira da Silva
}

\section{Resumo}

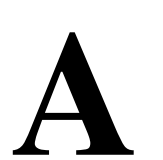

confiabilidade está relacionada ao grau de confiança de um sistema, o qual deve ser estabelecido em projeto, prevendo-se e especificando-se suas condições de operação. O Anexo E da norma apresenta resultados de uma ampla amostragem de diferentes espécies de dicotiledôneas e coníferas, com grande variação no número de exemplares, fixando um coeficiente de variação $(\mathrm{CV})$ para solicitações normais e tangenciais igual a $18 \%$ e $28 \%$, respectivamente. Este trabalho avaliou, com enfoque probabilístico, a distribuição de frequência de resistência à compressão paralela às fibras das amostras apresentadas no modelo normativo, buscando especificar-se o índice de confiabilidade estabelecido. Os resultados apontam que os dados propostos podem não ser normalmente distribuídos, acarretando distorções na obtenção da resistência característica. A adoção de um único coeficiente de variação para coníferas e dicotiledôneas não foi ratificada na análise dos dados e, ao se considerar a homogeneização de classes, também são gerados diferentes coeficientes de variação. Sobre a proposta de revisão da NBR 7190, conclui-se que a inclusão de mais uma classe de resistência (D50) melhora a distribuição das amostras, contudo, a supressão do Anexo E dificulta a categorização das classes por espécies.

${ }^{1}$ Rafael Barreto Castelo da Cruz ${ }^{1}$ Universidade Estadual de Campinas Campinas - SP - Brasil

${ }^{2}$ Luciano Ferreira dos Santos ${ }^{2}$ Universidade Estadual de Campinas Campinas - SP - Brasi

${ }^{3}$ Nilson Tadeu Mascia ${ }^{3}$ Universidade Estadual de Campinas Campinas - SP - Brasil

${ }^{4}$ Maria Cecilia Amorim Teixeira da Silva ${ }^{4}$ Universidade Estadual de Campinas Campinas - SP - Brasil

Recebido em 12/11/19 Aceito em 10/10/20
Palavras-chave: Madeira. Confiabilidade. Classes de resistência. Distribuição de frequência. Segurança estrutural.

\begin{abstract}
Reliability is related to the degree of reliability of a system, which must be established in the design, which should predict and specify its operating conditions. Annex E of standard NBR 7190:1997 for wooden structure projects presents results from a wide sampling of different dicotyledonous and coniferous species, with great variation in the number of specimens, fixing a coefficient of variation $(C V)$ for normal and shear strength equal to $18 \%$ and $28 \%$, respectively. This study evaluated, by using a probabilistic approach, the frequency distribution of samples of compressive strength parallel to the grain presented in the standard, seeking to specify the reliability index established. The results indicate that the data proposed may not be normally distributed, leading to distortions in the obtention of the characteristic strength. The adoption of a single coefficient of variation for the coniferous and dicotyledonous species is not ratified in the analysis of the data and, when considering the homogenisation of classes, different coefficients of variation are also generated. Regarding the proposed revision of NBR 7190, it is concluded that the inclusion of one more resistance class (D50) improves the distribution of the samples, however, the suppression of Annex $E$ hinders the categorisation of classes by species.
\end{abstract}

Keywords: Wood. Reliability. Strength classes. Sampling distribution. Structural safety.

CRUZ, R. B. C. da; SANTOS, L. F. dos; MASCIA, N. T.; SILVA, M. C. A. T. da. Análise de parâmetro normatizado para 277 projeto de estruturas de madeira considerando a confiabilidade estrutural. Ambiente Construído, Porto Alegre, v. 21, n. 2, p. 277-294, abr./jun. 2021. 


\section{Introdução}

O dimensionamento de uma estrutura é realizado sob condições de incertezas, por um lado, devido ao comportamento das ações e, por outro, devido ao comportamento da resistência de cada um dos materiais que a compõem.

Beeby (1994) e Ditlevsen e Madsen (1996) sugerem que a calibração de uma norma é uma atividade exercida por uma autoridade que, com referencial teórico adequado, pode atribuir valores às variáveis, tais como:

(a) valores nominais, médios ou característicos das variáveis (sejam ações ou resistências);

(b) coeficientes parciais de segurança; e

(c) fatores de redução ou modificação.

Ang e Tang (1975) indicam que critérios de segurança no cálculo estrutural foram definidos com base em julgamentos subjetivos. Segundo esses autores, com o aporte de ferramentas probabilísticas e métodos de simulação, passou a ser possível uma melhor definição dos critérios de segurança.

Já Nova (2017) sugere que os coeficientes parciais de segurança podem ser calibrados de tal forma que se possa otimizar o projeto da estrutura e ainda manter uma margem de segurança adequada.

A confiabilidade está relacionada ao grau de confiança de um sistema, o qual deverá ser estabelecido em projeto, prevendo-se e especificando-se as condições de operação do sistema. Dessa forma, a confiabilidade pode ser considerada uma probabilidade que reflete a segurança dos componentes estruturais e do sistema estrutural. Nesse contexto, avaliar estatisticamente as solicitações e as resistências pode contribuir para a definição de critérios normativos mais bem calibrados, como aponta Badimuena (2017), pois um caminho para justificar os critérios de segurança das normas é sua previsão associada a alguns conceitos de análise matemática, seja ela determinística ou probabilística. Esta análise permeia de alguma maneira a confiabilidade estrutural.

Vários estudos têm procurado identificar quais os fatores que afetam as propriedades físico-mecânicas da madeira e os que podem ser inerentes à própria madeira, como também ao ambiente onde a árvore se desenvolve.

De modo geral, admite-se que as resistências dos materiais tenham distribuições normais. $\mathrm{O}$ valor representativo básico adotado é a resistência característica inferior. O valor característico é uma estimação pontual, que depende da variabilidade dos dados amostrais. Portanto, é necessário que sejam apresentados os limites dentro dos quais a estimativa pode variar, que usualmente correspondente ao quantil de $5 \%$ da distribuição de resistências (FUSCO, 1976).

Correlacionando-se os parâmetros de confiabilidade com as propriedades mecânicas da madeira normatizadas, observa-se que os coeficientes parciais da norma vigente de projeto de estruturas de madeira, NBR 7190:1997 - Projeto de Estruturas de Madeira (ABNT, 1997), não foram calibrados com base na teoria da confiabilidade estrutural. Analisando-se os valores para a revisão da norma, pode-se dizer que os coeficientes parciais preservaram as características dos antigos coeficientes centrais, o que permite iniciar os estudos de calibração dessa norma com base na confiabilidade estrutural.

Alguns aspectos destacados neste artigo estão relacionados com a verificação da distribuição de resultados de resistências da madeira listados na NBR 7190 (ABNT, 1997), com a influência do coeficiente de variação na determinação das resistências características das espécies de madeiras coníferas e dicotiledôneas, e com as diferentes classes de resistências de madeiras, e, ainda, como esses fatores podem influenciar no índice de confiabilidade. A NBR 7190, com sua versão de 1997, é uma norma que, com mais de 2 décadas de utilização, vem passando por um extenso processo de discussão para sua revisão. Este trabalho, complementarmente, faz uma análise crítica do projeto de revisão, em andamento, no Brasil, da NBR 7190, coordenado pela Comissão de Estudo de Estruturas de Madeiras (CE 002:126.010) do Comitê Brasileiro da Construção Civil (ABNT/CB-002).

Nesse contexto, o objetivo deste trabalho é avaliar com enfoque probabilístico a distribuição de frequência de resistência à compressão paralela às fibras oriundas de amostras "do Anexo E" da NBR 7190 (ABNT, 1997), especificando o índice de confiabilidade que a norma garante aos projetos de estruturas de madeira.

De forma complementar, esta pesquisa analisa os impactos do projeto de revisão da norma, com a inclusão de classes de resistência para dicotiledôneas - também denominadas de folhosas, a partir de corpos de prova 
isentos de defeitos - classes de resistência de espécies de florestas nativas definidas em ensaios de corpos de prova isentos de defeitos - e de classes de resistência para coníferas e dicotiledôneas definidas em ensaios de peças estruturais, verificando o impacto da possível supressão das propriedades apresentadas por espécie na norma de 1997.

\section{Referencial teórico}

No Brasil, ao se especificar a madeira para o projeto estrutural, é habitual a escolha de espécies usuais, cujas propriedades mecânicas já foram investigadas e têm resultados de referência na NBR 7190:1997 - Projeto de Estruturas de Madeira (ABNT, 1997), em seu Anexo E. Outra maneira é permitir a utilização de classes de resistência, de tal modo que os valores das propriedades mecânicas sejam agrupados por lotes, independentemente de qual seja a espécie.

A utilização de classes de resistência elimina a necessidade da identificação botânica da madeira, pois num projeto estrutural desenvolvido de acordo com essa norma bastará a verificação da alocação das propriedades de resistência de um lote de peças de madeira à classe de resistência especificada no projeto.

Vilela, Mascia e Santos (2020) apontam que a variabilidade da madeira é consideravelmente grande e não deve ser negligenciada no projeto, e que, portanto, a análise probabilística é uma técnica alternativa capaz de estimar cargas para diferentes probabilidades de falha de acordo com cada critério de projeto.

Sales e Lahr (1996) apontam que a dificuldade no agrupamento está na variabilidade das propriedades mecânicas das madeiras, pois, diferentemente de materiais de construção, como o aço e o concreto, que possuem coeficiente de variação $(C V$ ou $\delta)$ com valores inferiores a $0,04(4 \%)$ e entre $0,10(10 \%)$ e 0,15 (15\%) respectivamente, as madeiras, segundo Freitas (1978) e Rocco Lahr (1990), possuem valores de coeficiente da variação da ordem de $0,18(18 \%)$, com teor de umidade $(U \%)$ de $12 \%$, considerando-se a umidade relativa do ambiente $\left(U_{a m b}\right)$ menor que $65 \%$. Entretanto, em trabalhos experimentais realizados pelos autores, para as dicotiledôneas, o coeficiente de variação apontou resultados entre 0,17 e 0,21.

Green e Kretschmann (1990) relatam que a distribuição dos limites das classes, quando associada a uma função matemática, permite a utilização simplificada de parâmetros homogêneos. Para as madeiras dicotiledôneas, a norma brasileira adota classes homogêneas de resistência característica à compressão paralela às fibras $\left(f_{c 0, k}\right)$, em quatro grupos para as dicotiledôneas (D20, D30, D40 e D60), e em três grupos para as coníferas (C20, C25 e C30). Consideram-se 43 espécies de dicotiledôneas e 7 espécies de coníferas.

Sales (2004) observa que projetistas podem encontrar dificuldades no conhecimento das espécies disponíveis no local de aplicação do projeto, optando pela especificação de espécies de uso tradicional, as quais podem ter custo elevado de aquisição devido à distância da região de extração.

O Anexo E da NBR 7190 (ABNT, 1997) apresenta uma relação de resultados de ensaios realizados no Laboratório de Madeiras e de Estruturas de Madeiras (LaMEM) da Escola de Engenharia de São Carlos (EESC), da Universidade de São Paulo. São 1.129 amostras das 43 espécies de dicotiledôneas, com variação entre 8 e 103 exemplares de cada espécie, e 281 amostras das 7 espécies de coníferas, com variação entre 15 e 99 exemplares de cada espécie, fixando um CV igual a $18 \%$ para solicitações normais, e igual a $28 \%$ para solicitações tangenciais.

São apresentados os valores médios de madeiras nativas e de florestamento, e o modelo de segurança adotado nessa norma é o método semiprobabilístico, especificamente o método dos estados limites, consistindo em se impor que os estados limites últimos somente possam ser atingidos quando, na seção da peça em que atuam as solicitações de cálculo, as resistências também tenham seus valores iguais às resistências de cálculo. As solicitações de cálculo são usualmente valores majorados, enquanto as resistências de cálculo são valores minorados.

Desse modo, o modelo de valores característicos considera a variabilidade dos valores e as variáveis que descrevem um sistema estrutural por meio de variáveis aleatórias (FUSCO, 1976, 1993; LIN; COROTIS, 1984). Assim sendo, para a determinação do valor característico de elementos estruturais de madeira deve ser utilizada a teoria de probabilidade em forma adequada, pois isso obviamente leva a uma estimativa mais precisa desse valor.

A distribuição de frequência é uma forma de agrupar amostras em intervalos de classes. A quantidade de intervalos de classe pode ser estimada pela regra empírica, denominada pela fórmula de Sturges, na qual o número $k$ de intervalos para cada conjunto de observações com $n$ valores pode ser calculado pela Equação 1 .

$k=1+3,3 \times \log _{10} n$

Eq. 1 
Adolfs (2011) e Meyer (2015) salientam que a quantidade de amostras dentro de um intervalo define a altura das barras e a frequência de medidas. Os valores podem ser absolutos, quando associados à quantidade total de amostras no intervalo, ou relativos, quando o número de amostras do intervalo é dividido pelo número total de amostras do experimento.

As distribuições probabilísticas podem ser graficamente representadas por um histograma, em que o eixo horizontal apresenta a classe de intervalos, e o eixo vertical, a quantidade de amostras (Figura 1), admitindo que a tensão $\mathrm{f}_{\text {co }}$ é a resistência.

\section{Distribuição de probabilidades e variáveis aleatórias}

Adolfs (2011) e Costa (2017) destacam que, quando são conhecidas as $n$ amostras de um experimento aleatório, podem-se estabelecer propriedades importantes que sintetizam as informações contidas nos dados originais, que são, na maioria dos casos, a média $(\mu)$ e a variância $\left(\sigma^{2}\right)$, sendo o desvio padrão $(\sigma)$ e o coeficiente de variação $(C V)$ derivados dos dois primeiros parâmetros.

Define-se a função $F$ como a função de distribuição acumulada da variável aleatória $X$, sendo $F(x)=P(X \leq$ $x$ ) (MEYER, 2015). Quando $X$ é uma variável aleatória contínua, $F(x)$ é calculada pela Equação 2:

$F(x)=\int_{-\infty}^{x} f(x) d x, \forall x \in \mathrm{R} \mathrm{e}-\infty<x<+\infty$

Eq. 2

Onde $f(x)$ é a função densidade de probabilidade.

\section{Curva de distribuição normal}

Uma das distribuições mais utilizadas na Engenharia, que descreve adequadamente propriedades mecânicas dos materiais de construção, é a distribuição normal, pois muitas populações (ou amostras) numéricas possuem as características dessa curva (DEVORE, 2006). A distribuição normal possui forma de sino, e a equação matemática de sua distribuição de probabilidade da variável aleatória contínua $x$ (Equação 3 ) depende de dois parâmetros a serem inseridos, a média $\mu$ e o desvio padrão $\sigma$.

$f(x ; \mu, \sigma)=\frac{1}{\sqrt{2 \pi \sigma}} e^{\frac{-(x-\mu)^{2}}{2 \sigma^{2}}}$

Algumas propriedades da função de densidade de probabilidade normal podem ser destacadas, tais como:

(a) o valor máximo de $f(x)$ corresponde ao seu ponto médio, isto é, a média da distribuição; e

(b) a função $f(x)$ apresenta dois pontos de inflexão simétricos em relação à média, que representam o desvio padrão da distribuição normal.

Figura 1 - Exemplo de histograma

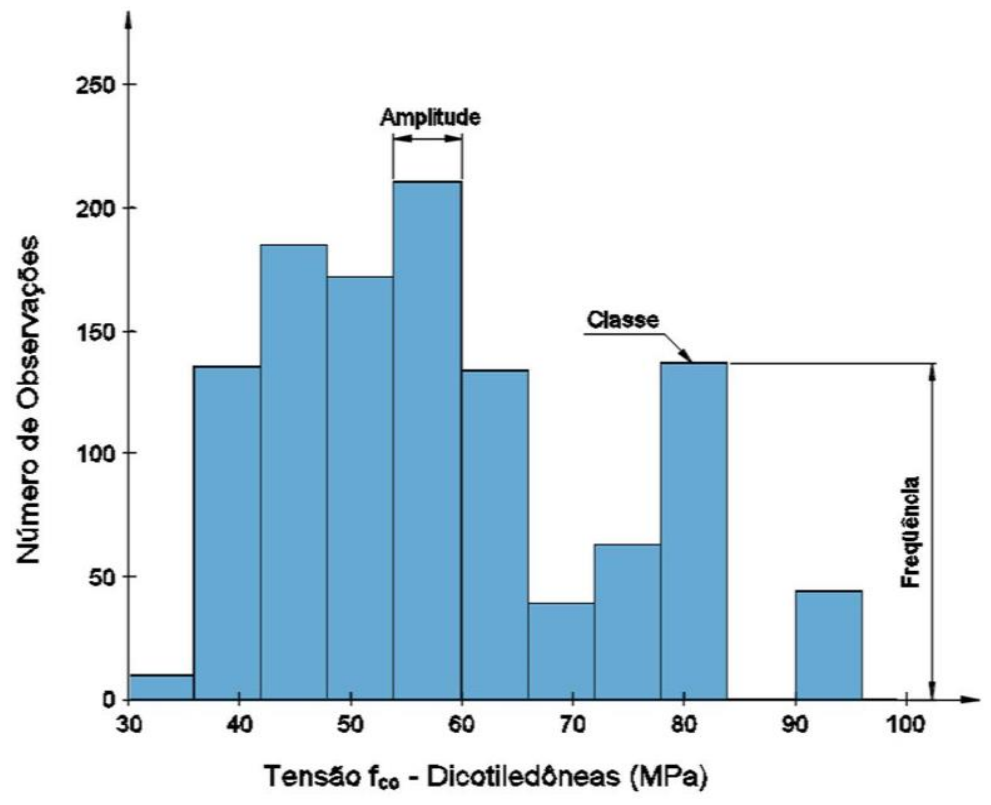

280 Cruz, R. B. C. da; Santos, L. F. dos; Mascia, N. T.; Silva, M. C. A. T. da 


\section{Curva de Distribuição Log-normal}

Segundo Devore (2006), uma distribuição log-normal depende dos parâmetros $\mu$ e $\sigma$, e é composta de uma variável não negativa $X$ se a variável $Y=\ln (x)$ possui uma distribuição normal e é representada pelas Equações 4 e 5.

$f(x ; \mu ; \sigma)=\frac{1}{\sqrt{2 \pi} \sigma x} e^{\frac{-[\ln (x)-\mu]^{2}}{\left(2 \sigma^{2}\right)}}$

Onde $x \geq 0$.

$f(x ; \mu ; \sigma)=0$

Onde $x<0$.

Os parâmetros $\mu$ e $\sigma$, nesse caso, são a média e o desvio padrão associados a $\ln (x)$ e podem ser determinados, de acordo com Walpole et al. (2015), pelas Equações 6 e 7.

$\mu=e^{\mu+\frac{\sigma^{2}}{2}}$

$\sigma^{2}=e^{2 \mu+\sigma^{2}}\left(e^{\sigma^{2}}-1\right)$

Eq. 7

Algumas propriedades da função de densidade de probabilidade da distribuição log-normal podem ser destacadas, tais como:

(a) $f(x)$ é assimétrica à esquerda em relação à média ( $\mu$ ); $\mathrm{e}$

(b) $f(x)$ apresenta dois pontos de inflexão simétricos em relação à média, que representam o desvio padrão da distribuição normal.

\section{Curva de Distribuição Weibull}

Costa (2017) aponta que o modelo de distribuição de probabilidades de Weibull é uma função semiempírica. Uma das vantagens da análise de Weibull é que ela propõe uma solução gráfica simples. O processo consiste em plotar a curva e analisá-la com a notação $X \sim W(\beta, \eta, \varepsilon)$.

A variável contínua de distribuição de Weibull baseia-se em três parâmetros:

(a) parâmetro de escala $(\eta)$, que define a escala ou amplitude da função, e é um número dimensional, de mesma unidade da variável $X$, que pode assumir apenas valores reais positivos, no intervalo $0<\eta \leq+\infty$;

(b) parâmetro de forma $(\beta)$, que é um número adimensional, que define a forma da função de densidade de probabilidade, também conhecido por parâmetro de declividade de Weibull, pois determina a declividade da função de distribuição acumulada plotada em um papel de probabilidade Weibull - o coeficiente de variação da variável aleatória $X \sim \operatorname{Weibull}(\beta, \eta, \varepsilon)$ depende apenas do parâmetro de forma; e

(c) parâmetro local $(\varepsilon)$, que é um parâmetro de localidade da distribuição que caracteriza a translação no gráfico, sendo um número dimensional, de mesma unidade da variável $X$, que pode assumir qualquer valor real, no intervalo $-\infty \leq \varepsilon \leq+\infty$.

A função densidade de probabilidade de Weibull é expressa pela Equação 8.

$f(x ; \beta ; \eta ; \varepsilon)=\frac{\beta}{\eta} \times\left(\frac{x-\varepsilon}{\eta}\right)^{\beta-1} \times e^{\left(\frac{x-\varepsilon}{\eta}\right)^{\beta}}$

As expressões que caracterizam a média e a variância são obtidas pelas Equação 9 e 10 respectivamente:

$E(\beta, \eta)=\varepsilon+\eta \Gamma\left(\frac{\beta+1}{\beta}\right)$

$\operatorname{VAR}(\eta, \beta)=\eta^{2}\left[\Gamma\left(\frac{\beta+2}{\beta}\right)-\Gamma\left(\frac{\beta+1}{\beta}\right)\right]^{2}$

Pela versatilidade, a distribuição de Weibull proporciona muitas aplicações na Teoria da Confiabilidade (SIMONETTI et al., 2009).

\section{Teste do Kolmogorov-Smirnov}

Conforme Viali (2008), grande parte dos problemas em Estatística é tratada com a hipótese de que os dados são retirados de uma população com uma distribuição de probabilidade específica. O formato dessa 
distribuição pode ser um dos objetivos da análise e, nesse sentido, surge a necessidade de verificar se essa suposição pode ser assumida.

Em alguns casos, assumir a normalidade dos dados é o primeiro passo para simplificar a análise, e para dar suporte a essa suposição aplica-se, entre outros, o teste de Kolmogorov-Smirnov. Esse teste pode ser utilizado para avaliar as seguintes hipóteses:

(a) se $H_{0}$, os dados seguem determinada distribuição; e

(b) se $H_{l}$, os dados não seguem determinada distribuição.

O teste verifica a máxima diferença absoluta entre a função de distribuição acumulada assumida para os dados e a função de distribuição empírica dos dados. Como critério, essa diferença é comparada com um valor crítico, para dado nível de significância, chamado $p$-value ou $\alpha$. No teste de Kolmogorov-Smirnov considera-se o parâmetro $D_{n}$, conforme a Equação 11, como uma medida da discrepância entre a função de distribuição da amostra $F_{n}$ e a função de distribuição proposta $F_{0}$.

Observa-se que $D_{n}$ representa a distância vertical máxima entre as imagens da função de distribuição da amostra, $F_{n}(x)$ e da função de distribuição proposta $F_{0}(x)$, dando assim uma ideia do ajustamento.

$D_{n}=\frac{\sup }{-\infty<x<+\infty}\left|F_{n}(x)-F_{0}(x)\right|$

Conhecendo-se a distribuição de $D_{n}$, é possível avaliar seu valor e decidir se ele é suficientemente pequeno para que não se rejeite $H_{0}$ a dado nível de significância $\alpha$. Mais efetivamente, rejeita-se $H_{0}$ para um nível de significância $\alpha$ se o valor observado do parâmetro teste $D_{n}$ for superior ou igual ao ponto crítico $D_{n, \alpha}$, onde $D_{n, \alpha}$ é tal que atenda à condição da Equação 12.

$P\left(D_{n} \geq D_{n, \alpha} \backslash H_{0}\right.$ é verdadeira $)=\alpha$

Eq. 12

Para a significância $(\alpha)$, adotam-se na literatura valores entre 0,01 (1\%) e 0,2 (20\%), sendo o mais usual 0,05 $(5 \%)$.

\section{Confiabilidade estrutural e índice de confiabilidade $B$}

A partir das primeiras publicações na década de 1960 e com o desenvolvimento das técnicas para a resolução de problemas de confiabilidade, normas de projeto estruturais baseadas na probabilidade começaram a ser formuladas. Galambos et al. (1982) publicaram a primeira versão da Load Resistance Factor Design (LRFD) para edifícios de aço com base em estudos realizados no final da década de 70 e início da década de 80. Esse estudo se prolongou até 1985 (ELLINGWOOD, 2000).

Em 1971 foi criado o Joint Committee on Structural Safety (JCSS), um comitê formado por vários profissionais de países da Europa para desenvolver pesquisas na área de confiabilidade e segurança estrutural (VROUWENVELDER, 1997).

No Eurocode 5, ou estabelecido em 1995, os índices de confiabilidade de referência já são mencionados. Na versão de 2004 (COMITÉ..., 2004), o valor de $\beta$ sugerido para o estado limite último é igual a 3,8.

Trabalhos como Cheung, Pinto e Calil Junior (2011), Cheung et al. (2017) e Vilela, Mascia e Santos (2020) estudaram a confiabilidade das estruturas de madeira em âmbito nacional, mas nenhum diretamente voltado à análise dos dados experimentais sugeridos no Anexo E da NBR 7190 (ABNT, 1997), sobretudo sob o olhar da confiabilidade estrutural.

A probabilidade de falha $\left(P_{f}\right)$ é a medida de violação da segurança estrutural e é uma forma de verificar qual a probabilidade de um estado limite ser ultrapassado, ou melhor, qual a probabilidade de um modo de falha ser alcançado.

Considerando-se uma variável denominada genericamente de $G$, que pode ser entendida como a margem de segurança existente entre as variáveis analisadas, a variável $R$, relativa à resistência, e a $S$, relativa à solicitação. A variável $G$ fica definida pela Equação 13, chamada de função de desempenho. A probabilidade de falha do problema analisado, ou seja, a probabilidade de a variável $R$ ser superada pela variável $S$ é obtida pela Equação 14:

$G=R-S$

Eq. 13

$P f=P(G<0) \therefore P f=\int_{-\infty}^{0} f(G) \cdot d g$

Eq. 14

Sendo $f(G)$ a função de distribuição de probabilidades da variável $G$.

282 Cruz, R. B. C. da; Santos, L. F. dos; Mascia, N. T.; Silva, M. C. A. T. da 
Geralmente, os problemas que envolvem resistências e solicitações costumam ser calculados com funções de duas ou mais variáveis aleatórias. Portanto, a probabilidade de falha depende dos valores estatísticos das funções de distribuição que melhor representam a variável aleatória de interesse, aponta Santiago (2019).

Santos (2014) observa que o First Order Reliability Moment (FORM) é um método de transformação que calcula a probabilidade de falha a partir do índice de confiabilidade $\beta$, o qual é dependente da função desempenho utilizada. Essa formulação, entretanto, apresenta diversas restrições como a necessidade de que as variáveis aleatórias sejam todas normais e independentes, e que a função de falha seja linear.

\section{Método}

O método de investigação empregado neste trabalho foi composto de três etapas:

(a) levantamento e análise estatística de experimentos no modelo normativo da NBR 7190 (ABNT, 1997);

(b) quantificação e interpretação das distribuições dos dados e verificação da adequabilidade dos dados às distribuições estatísticas propostas na norma; e

(c) análise de confiabilidade.

O levantamento e a análise estatística de experimentos no modelo normativo da NBR 7190 (ABNT, 1997) foram realizados de forma exploratória, a partir de trabalhos experimentais realizados no LaMEM,

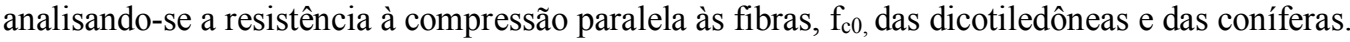

Como base de estudo para confiabilidade utilizou-se o dimensionamento à compressão simples de elementos estruturais. Cada exemplar, de cada espécie apresentada pelo Anexo E da NBR 7190 (ABNT, 1997), gerou uma amostra de tensão resistente característica à compressão $\left(R_{k}\right)$, e a partir da aplicação dos coeficientes de minoração propostos na norma, para cada exemplar de cada espécie, foram obtidas as tensões solicitantes características à compressão $\left(S_{k}\right)$. O dimensionamento foi feito conforme preconiza a NBR 7190 (ABNT, 1997), de acordo com os procedimentos padrão para a obtenção das resistências de cálculo das peças estruturais submetidas à compressão simples.

Nas etapas de quantificação, interpretação das distribuições dos dados e verificação da adequabilidade dos dados às distribuições estatísticas propostas na norma, foi avaliado se a distribuição segue com homogeneidade uma distribuição normal, log-normal ou Weibull, a partir do teste de Kolmogorov-Smirnov, que quantifica a distância entre a função distribuição empírica da amostra e a função distribuição acumulada da distribuição de referência. Ambos os testes foram considerados a 5\% de significância.

A análise de confiabilidade foi realizada com a utilização de toda a informação estatística sobre os dados obtidos no levantamento das espécies e dos valores encontrados para solicitações em uma estrutura. Esses elementos foram colocados em equações de estados limites e foram realizadas as análises com o método FORM, tanto para as dicotiledôneas quanto para as coníferas, de acordo com as classes de resistência existentes na norma, para se verificar o índice de confiabilidade $(\beta)$, ajustando-se os dados a uma distribuição de probabilidade normal.

Os métodos de transformação são técnicas utilizadas no cálculo de probabilidades de falha das estruturas, tendo base na transformação das variáveis aleatórias em variáveis do tipo normal padrão equivalente. Entre esses métodos destaca-se o FORM, que, conforme Santiago (2019), segue o conceito proposto por Cornell (1969), no qual o índice de confiabilidade é a razão entre a média e o desvio padrão da função estado limite. Também de acordo com Hasofer e Lind (1974) e Rackwitz e Fiessler (1978), que estabelecem que o índice de confiabilidade representa a menor distância entre a média da função de desempenho à superfície de falha, esses pressupostos podem ser avaliados a partir de uma distribuição normal.

Se as variáveis de resistência $R$ e de solicitação $S$ forem independentes, a probabilidade de falha pode ser calculada pelo somatório do produto entre as funções densidade de probabilidade de $R$ e $S$. Entretanto, a função resultante é deveras complexa para sua integração, e, portanto, são adotados métodos aproximados ou simulados para se determinarem os resultados. Na análise segundo a teoria da confiabilidade de propriedades estruturais, muitos autores, tais como Cornell (1969), Ditlevsen e Madsen (1996), MacGregor (1976) e Tramontini (2016), admitem, por simplificação, que as variáveis têm distribuição normal.

Mitre (2005) indica que, sendo as variáveis aleatórias $R$ e $S$ independentes e com distribuição normal de probabilidades, a margem de segurança será também uma variável aleatória com média e desvio padrão conhecidos, conforme as Equações 15 e 16.

$G=R-S \therefore \mu_{G}=\mu_{R}-\mu_{S}$

Eq. 15 
$\sigma_{G}=\sqrt[2]{\sigma_{R}^{2}-\sigma_{S}^{2}}$

Eq. 16

A Figura 2a ilustra a probabilidade de falha quando as variáveis $R$ e $S$, ambas com distribuição normal, são consideradas. A Figura 2 b apresenta a probabilidade de falha em função da variável $G$.

A condição limite de segurança pode ser obtida pela Equação 17, e o coeficiente de confiabilidade $\beta$ é calculado pela Equação 18:

$0=\mu_{G}-\left(\beta_{G} * \sigma_{G}\right) \therefore \mu_{G}=\left(\beta_{G} * \sigma_{G}\right) \therefore \mu_{R}-\mu_{S}=\left(\beta_{G} * \sigma_{G}\right)$

Eq. 17

$\beta=\frac{\mu_{R}-\mu_{S}}{\sqrt[2]{\sigma_{R}^{2}-\sigma_{S}^{2}}}$

Os resultados obtidos apresentam as variações do coeficiente de variação $(C V$ ou $\delta)$, do desvio padrão $(\sigma) \mathrm{e}$ do índice de confiabilidade $(\beta)$ para cada grupo de análise.

\section{Resultados e discussões}

O levantamento e a análise estatística de experimentos no modelo normativo da NBR 7190 (ABNT, 1997) foram realizados de forma exploratória a partir de trabalhos experimentais, analisando-se a resistência à compressão paralela às fibras, $f_{c 0}$, das dicotiledôneas e das coníferas.

\section{Resultados para as dicotiledôneas a partir da NBR 7190:1997}

Nas dicotiledôneas, o Anexo E apresenta 43 espécies diferentes, das quais são totalizadas 1.129 amostras, ensaiadas pela norma. Foram consideradas, inicialmente, para cada espécie exatamente o número de amostras ensaiadas $n$, todas com a tensão resistente à compressão paralela às fibras $f_{c o}$, conforme a Tabela 1 .

Conforme o histograma na Figura 3a, observou-se que os dados, provavelmente, não têm uma distribuição que evidentemente possa ser considerada como uma distribuição normal.

A Figura $3 b$ apresenta as distribuições acumuladas de probabilidade dos dados, uma distribuição normal, uma log-normal, e uma de Weibull, para ajudar nessa percepção com as funções de densidade acumuladas.

Figura 2 - Probabilidade de Falha

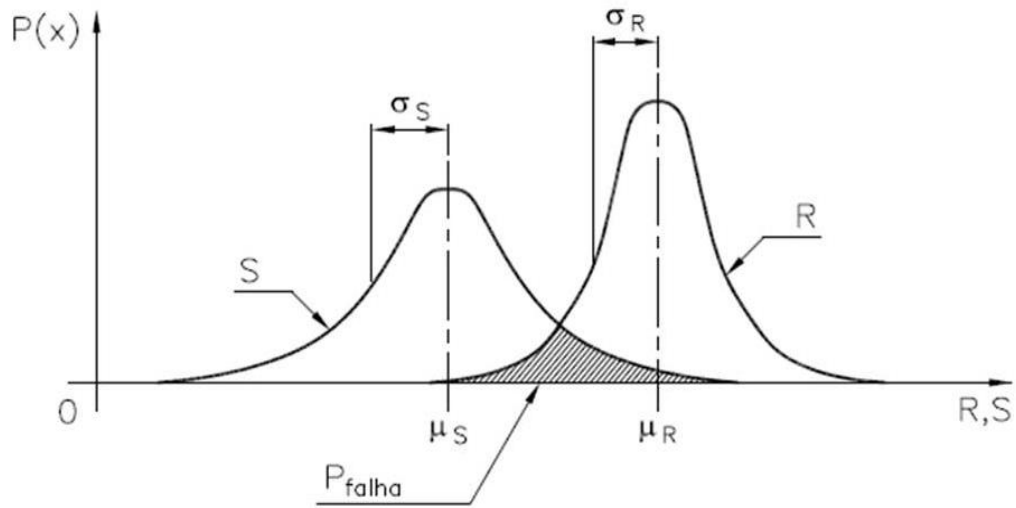

(a) R, S

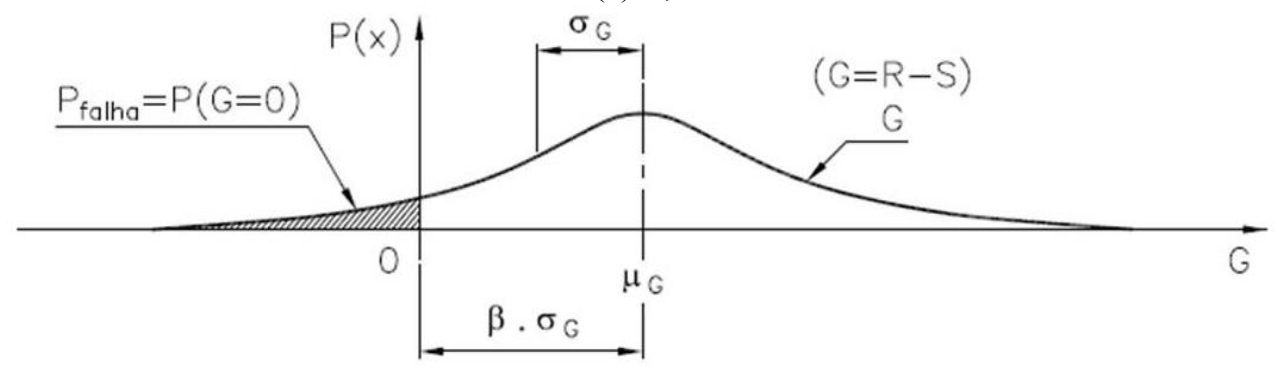

(b) G

Fonte: adaptada de Mitre (2005). 
Tabela 1 - Resistência à compressão e número de exemplares para dicotiledôneas

\begin{tabular}{|c|c|c|c|c|c|}
\hline $\boldsymbol{f}_{\boldsymbol{c} \boldsymbol{0}}(\mathbf{M P a})$ & $\boldsymbol{n}$ (Amostras) & $\boldsymbol{f}_{\boldsymbol{c} \boldsymbol{0}}$ (MPa) & $\boldsymbol{n}$ (Amostras) & $\boldsymbol{f}_{\boldsymbol{c} \boldsymbol{0}}$ (MPa) & $\boldsymbol{n}$ (Amostras) \\
\hline $\mathbf{5 0 , 5}$ & 15 & 47,3 & 24 & 95,2 & 12 \\
$\mathbf{7 9 , 5}$ & 20 & 48 & 18 & 79,5 & 10 \\
$\mathbf{5 9 , 8}$ & 39 & 62 & 68 & 78,5 & 70 \\
$\mathbf{7 6 , 7}$ & 12 & 51,8 & 21 & 46,8 & 67 \\
$\mathbf{4 8 , 1}$ & 10 & 48,9 & 15 & 57,7 & 29 \\
$\mathbf{5 9 , 1}$ & 11 & 40,3 & 103 & 53,9 & 8 \\
$\mathbf{5 2}$ & 12 & 63,5 & 53 & 42,7 & 8 \\
$\mathbf{5 6}$ & 31 & 48,3 & 10 & 83,8 & 13 \\
$\mathbf{5 4 , 8}$ & 12 & 54,9 & 31 & 69,9 & 12 \\
$\mathbf{3 9}$ & 21 & 72,7 & 29 & 37,8 & 11 \\
$\mathbf{3 1 , 5}$ & 10 & 51,6 & 63 & 82,9 & 12 \\
$\mathbf{9 3 , 2}$ & 12 & 54,4 & 33 & 71,4 & 16 \\
$\mathbf{5 6 , 5}$ & 24 & 62,4 & 13 & 46 & 86 \\
$\mathbf{7 8 , 4}$ & 12 & 76 & 22 & 93,3 & 20 \\
$\mathbf{7 1 , 4}$ & 11 & & & & \\
\hline
\end{tabular}

Fonte: adaptada do Anexo E da NBR 7190 (ABNT, 1997).

\section{Figura 3 - Histograma e função acumulada das amostras de dicotiledôneas}

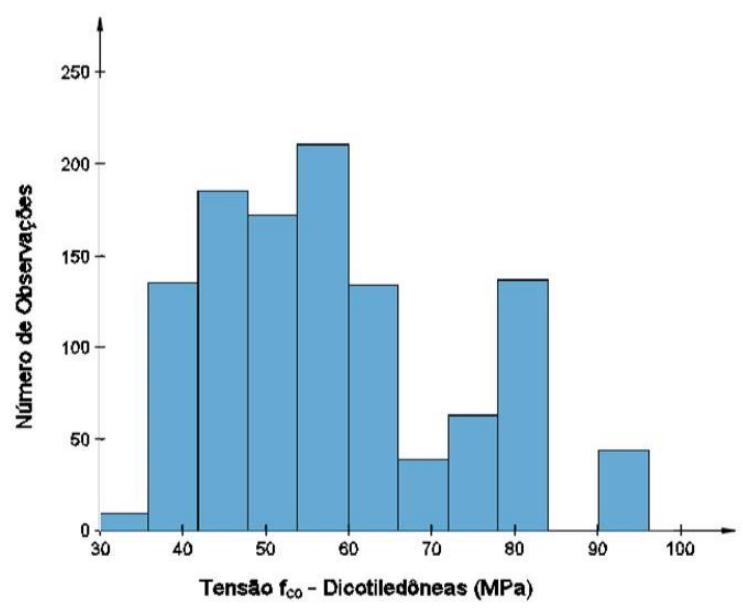

(a) Histograma

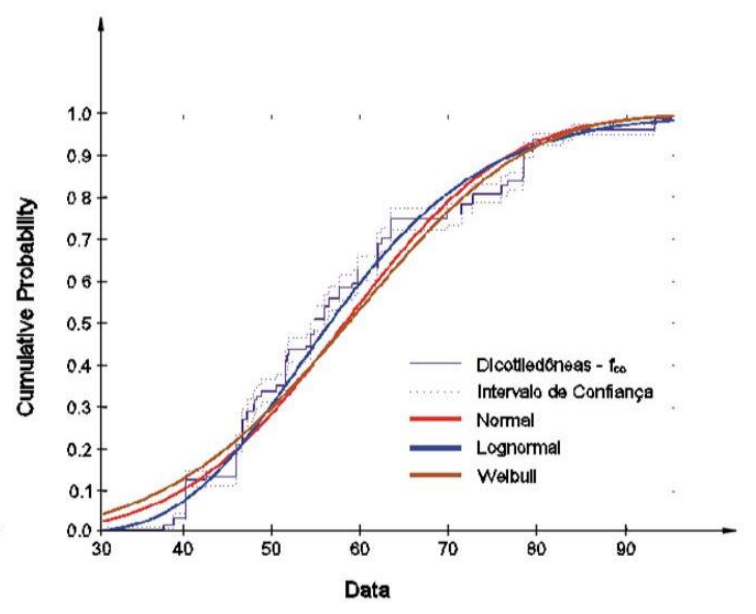

(b) Função acumulada

Os resultados indicaram média $(\mu)$ de 58,26 $\mathrm{MPa}$, desvio padrão $(\sigma)$ de $14,45 \mathrm{MPa}$, e coeficiente de variação $(C V)$ de $24,80 \%$, diferente dos $18 \%$ propostos pela norma.

Ao realizar os testes de significância Kolmogorov-Smirnov, notou-se que os dados têm 99,99\% de chance de não atingirem uma significância menor que 0,05 $(\alpha<5 \%)$ para as distribuições normal e Weibull, e 89,99\% de chance de não atingirem uma significância menor que $0,05(\alpha<5 \%)$ para a distribuição log-normal.

Esta análise implica uma consequência, pois ao considerar que os dados são normais, a NBR 7190 (ABNT, 1997) faz com que a resistência característica inferior, correspondente ao quantil de $5 \%$ da distribuição de resistências, seja obtida pela Equação 19:

$f k=f m(1-1,645 \times \delta)$

Eq. 19

E partindo-se do pressuposto que o coeficiente de variação $(\delta)$ é $18 \%$, a resistência característica pode ser obtida pela Equação 20:

$f k=f m(1-1,645 \times \delta) \therefore f k=f m \times 0,70$

Eq. 20

Por exemplo, ao se assumir que a média $\left(\mu=f_{m}\right)$ é igual a $58,26 \mathrm{MPa}$, uma resistência à compressão característica $\left(f_{c o, k}\right)$ resulta no valor de $40,78 \mathrm{MPa}$. Entretanto, os dados podem não seguir a distribuição normal, e possuir coeficiente de variação diferente de $18 \%$, como foi verificado na análise. Contudo, se o 
pressuposto de distribuição normal for mantido para os dados e, se apenas o coeficiente de variação for corrigido para $24,28 \%$, a resistência característica $f_{k}$ passa a ser obtida pela Equação 21:

$f k=f m(1-1,645 \times \delta) \therefore f k=f m \times 0,59$

Para essa nova consideração, ao se assumir que a média $\left(\mu=f_{m}\right)$ é $58,26 \mathrm{MPa}$, ter-se-ia uma resistência à compressão característica $\left(f_{c 0, k}\right)$ de $34,42 \mathrm{MPa}$. Assim evidencia-se que, para o caso genérico das dicotiledôneas, a norma pode apresentar valores de resistências características maiores, quando comparados com dados amostrais.

Aplicando-se a Equação 20 (proposta pela norma) e a Equação 21 (proposta pela análise amostral), é possível verificar o número de exemplares dentro de cada classe homogênea de resistência (D20, D30, D40 e D60), apresentados na Tabela 2.

Observa-se que os parâmetros da norma geram mais exemplares com resistências características que podem ser categorizados como D30 e D40. Contudo, ajustando os dados ao coeficiente de variação das amostras, na realidade, mais exemplares estão em D20 e D30. Chama a atenção, quando se aplica o modelo corrigido pelas amostras, que não são gerados exemplares categorizados como D60, e ainda, que 10 exemplares, não podem ser incluídos como D20, pois não atendem uma resistência à compressão paralela às fibras superior a $20 \mathrm{MPa}$.

Gerando-se hipoteticamente para cada uma das resistências características, uma solicitação característica, empregando-se todas as informações disponíveis obtidas no levantamento, ou seja, cada amostra de resistência à compressão característica $\left(R_{k}\right)$, gerou uma amostra de solicitação à compressão característica $\left(S_{k}\right)$, conforme Figura 4. Esse procedimento foi realizando minorando as resistências com a utilização dos coeficientes de modificação $\mathrm{k}_{\text {mod }}$ e do coeficiente de ponderação para estados limites últimos decorrentes de tensões de compressão paralela às fibras. Portanto $S_{k}=R_{k} x k_{\text {mod }} x \gamma$.

Com a utilização de toda a informação estatística dos dados, obtida no levantamento das espécies, e dos valores encontrados para as solicitações atuantes na estrutura, foram realizadas as análises com o FORM (First Order Reliability Moment). Este processo foi realizado para as 1129 amostras, e também para as classes homogêneas de resistência obtidas na Tabela 2.

Tabela 2 - Número de amostras em cada classe homogênea de resistência das espécies dicotiledôneas

\begin{tabular}{|c|c|c|}
\hline & Norma & Amostras \\
\hline D20 & 153 exemplares & 388 exemplares \\
\hline D30 & 480 exemplares & 448 exemplares \\
D40 & 452 exemplares & 283 exemplares \\
D60 & 44 exemplares & 0 exemplares \\
Total & 1129 exemplares & 1119 exemplares \\
\hline
\end{tabular}

Figura 4 - Histograma e distribuição das resistências e solicitações para dicotiledôneas

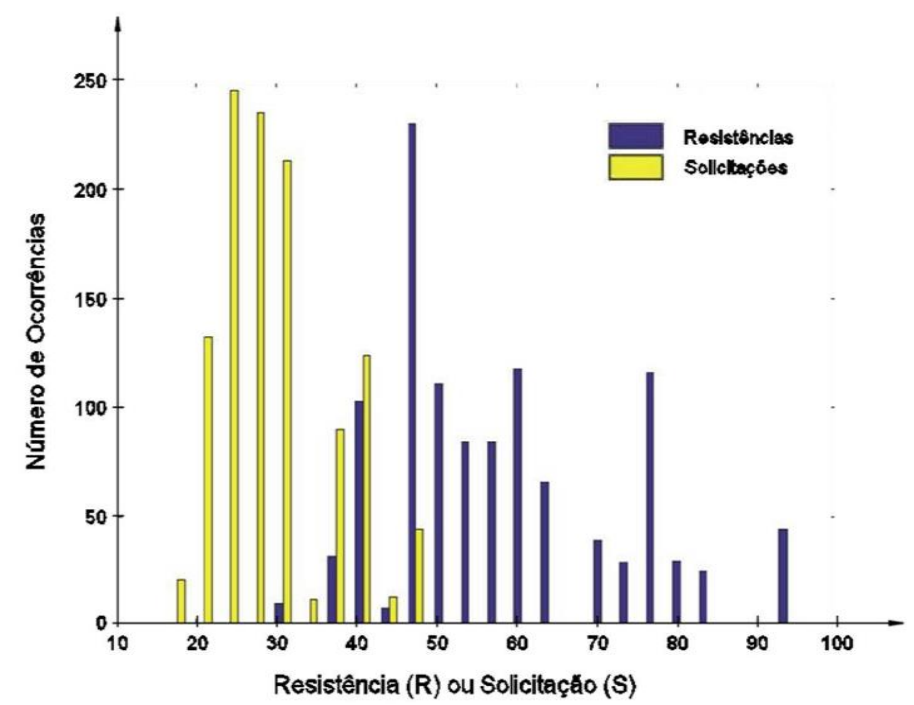

286 Cruz, R. B. C. da; Santos, L. F. dos; Mascia, N. T.; Silva, M. C. A. T. da 
Nota-se, na Tabela 3, que o índice de confiabilidade é fortemente influenciado pelo coeficiente de variação e, que pequenas alterações no $C V$ geram impactos relevantes no índice de confiabilidade.

Outra observação importante refere-se à madeira engenheirada (item 6.3.5 da NBR 7190 (ABNT, 1997)), a qual pode garantir a homogeneidade dos lotes, aumenta consideravelmente o índice de confiabilidade, que no caso em análise variou de 1,7 a 46. Contudo, as madeiras de classe D40, para o caso de aplicação do modelo proposto pela norma, não atingem o índice de confiabilidade proposto pelo Eurocode 5 (COMITÉ..., 2004), conforme Tabela 3.

Além disso, a proposta de ajuste do coeficiente de variação, que mantém as diferentes classes de resistências, oferece uma ordem de grandeza do índice de confiabilidade muito mais próxima do que a proposta da NBR 7190:1997 para as dicotiledôneas.

\section{Resultados para as Coníferas a partir da NBR 7190:1997}

Similar sequência de análise foi utilizada para as coníferas, ou seja, para as 281 amostras ensaiadas pela norma das 7 espécies que constam no seu Anexo E. Inicialmente foram considerados para cada espécie, exatamente o número de amostras ensaiadas $(n)$ todas com a Tensão Resistente à Compressão Paralela às fibras $f_{c 0}$ do Anexo E da NBR 7190 (ABNT, 1997).

Conforme o histograma da Figura 5a, constatou-se que os dados não têm uma distribuição que possa ser considerada como normal. Na Figura $5 b$ foram plotadas a distribuição acumulada de probabilidade dos dados, uma distribuição normal, uma log-normal, e uma de Weibull, sendo possível observar a discrepância dos resultados.

Os resultados apontaram uma média $(\mu)$ de 40,74 $\mathrm{MPa}$, um desvio padrão $(\sigma)$ de 3,75 $\mathrm{MPa}$, e um coeficiente de variação $(C V)$ de $9,21 \%$, diferente dos $18 \%$ propostos pela norma.

Tabela 3 - Síntese do Índice de Confiabilidade aplicado à compressão simples em dicotiledôneas

\begin{tabular}{|c|c|c|c|c|c|c|c|c|c|c|}
\hline & \multicolumn{1}{|c}{ Norma } \\
& $\begin{array}{c}\boldsymbol{\mu} \\
(\mathbf{M P a})\end{array}$ & $\begin{array}{c}\boldsymbol{\sigma} \\
(\mathbf{M P a})\end{array}$ & $\boldsymbol{\delta}$ & $\boldsymbol{\beta}$ & $\boldsymbol{n}$ & $\begin{array}{c}\boldsymbol{\mu} \\
(\mathbf{M P a})\end{array}$ & $\begin{array}{c}\boldsymbol{\sigma} \\
(\mathbf{M P a})\end{array}$ & $\boldsymbol{\delta}$ & $\boldsymbol{\beta}$ & $\boldsymbol{n}$ \\
D20 & 27,644 & 1,630 & $5,90 \%$ & 7,396 & 155 & 26,302 & 2,130 & $8,10 \%$ & 5,386 & 388 \\
D30 & 35,271 & 2,581 & $7,32 \%$ & 5,962 & 480 & 33,877 & 2,479 & $7,32 \%$ & 5,9617 & 448 \\
D40 & 48,615 & 5,841 & $12,0 \%$ & 3,617 & 450 & 46,970 & 4,172 & $8,88 \%$ & 4,9115 & 283 \\
D60 & 65,653 & 0,611 & $0,9 \%$ & 46,862 & 44 & - & - & - & - & 0 \\
\hline Amostras Totais & 58,260 & 14,448 & $24,8 \%$ & 1,7593 & 1129 & - & - & - & - & \\
\hline
\end{tabular}

Figura 5 - Histograma e função acumulada das amostras de coníferas

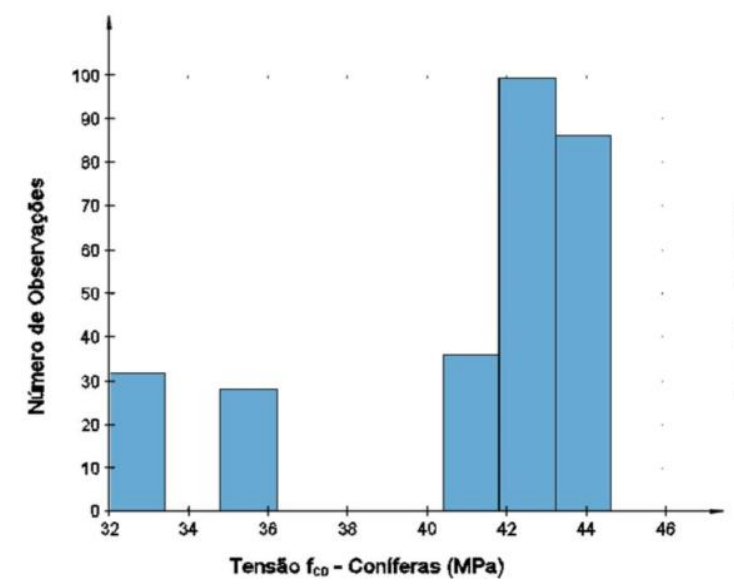

(a) Histograma

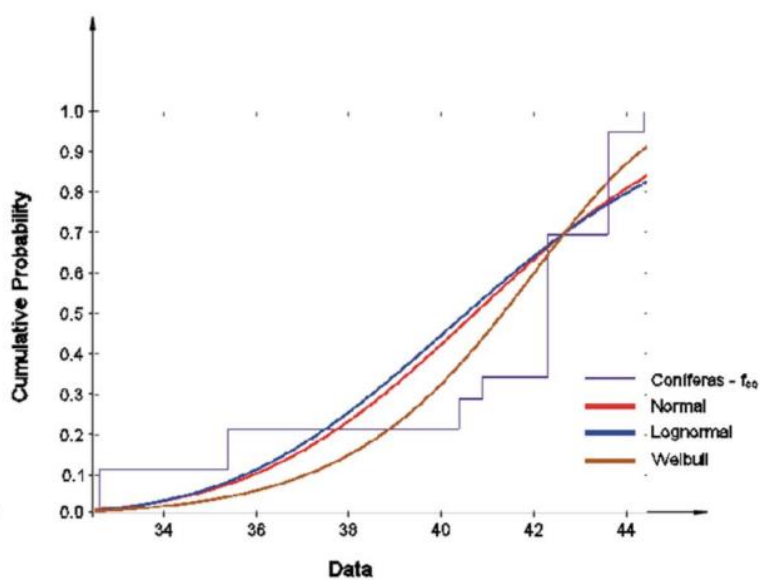

(b) Função acumulada 
Ao realizar os testes de significância Kolmogorov-Smirnov, notou- se que os dados têm 99,99\% de chance de não atingirem uma significância menor que $0,05(\alpha<5 \%)$ para a distribuição normal e log-normal, e têm $79,99 \%$ de chance de não atingirem uma significância menor que $0,05(\alpha<5 \%)$ para a distribuição Weibull.

Essa análise implica uma consequência, pois, ao adotar que os dados são normais, a NBR 7190 (ABNT, 1997) faz com que a chamada resistência característica inferior, correspondente ao quantil de $5 \%$ da distribuição de resistências, seja obtida pela Equação 22:

$f k=f m(1-1,645 \times \delta)$

Eq. 22

Partindo-se do pressuposto de que o coeficiente de variação $(\delta)$ é igual a $18 \%$, a resistência característica pode ser obtida pela Equação 23:

$f k=f m(1-1,645 \times \delta) \therefore f k=f m \times 0,70$

Por exemplo, ao se assumir que a média $\left(\mu=f_{m}\right)$ é igual a $40,74 \mathrm{MPa}$, uma resistência à compressão característica $\left(f_{c 0, k}\right)$ de $28,51 \mathrm{MPa}$ seria obtida. Entretanto, os dados podem não seguir a distribuição normal, e possuir coeficiente de variação diferente de $18 \%$, como foi verificado na análise. Contudo, se o pressuposto de distribuição normal for mantido para os dados, e se apenas o coeficiente de variação for corrigido para 9,21\%, a resistência característica $f_{k}$ passa a ser obtida pela Equação 24:

$f k=f m(1-1,645 \times \delta) \therefore f k=f m \times 0,84$

Eq. 24

Para essa nova consideração, ao se assumir que a média $\left(\mu=f_{m}\right)$ é igual a $40,74 \mathrm{MPa}$, se terá uma resistência à compressão característica $\left(f_{c 0, k}\right)$ de $34,54 \mathrm{MPa}$. Assim, evidencia-se que, para o caso genérico das coníferas, a norma pode apresentar valores de resistências características menores, quando comparado com dados amostrais. Pelo processo da amostragem, a média das coníferas ficou muito próximo da média das dicotiledôneas, contudo com um coeficiente de variação menor.

Aplicando-se a Equação 23 (proposta pela norma) e a Equação 24 (proposta pela análise amostral), é possível obter o número de exemplares dentro de cada classe homogênea de resistência (C20, C25 e C30), apresentados na Tabela 4 .

Observa-se que os parâmetros da norma geram mais exemplares com resistências características que podem ser categorizados como C25, mas, quando se aplica o modelo corrigido pelas amostras, evidencia-se que a maior parte dos exemplares pode ser categorizada como $\mathrm{C} 30$

O processo de análise probabilística de confiabilidade nas coníferas foi realizado com o mesmo procedimento metodológico das dicotiledôneas. Observa-se que, para a madeira engenheirada (ou seja, em classe), e já verificada anteriormente também para o caso das dicotiledôneas, o índice de confiabilidade aumenta consideravelmente, conforme Tabela 5.

Tabela 4 - Número de amostras em cada classe homogênea de resistência das espécies coníferas

\begin{tabular}{c|c|c}
\multicolumn{1}{c}{ Norma } & Amostras \\
\hline C20 & 60 exemplares & 0 exemplares \\
C25 & 135 exemplares & 32 exemplares \\
C30 & 86 exemplares & 249 exemplares \\
\hline
\end{tabular}

Tabela 5 - Síntese do índice de confiabilidade aplicado à compressão simples em coníferas

\begin{tabular}{|c|c|c|c|c|c|c|c|c|c|c|}
\hline & \multicolumn{5}{|c|}{ Norma } & \multicolumn{5}{|c|}{ Amostras } \\
\hline & $\mu(\mathbf{M P a})$ & $\begin{array}{c}\sigma \\
(\mathbf{M P a})\end{array}$ & $\delta$ & $\beta$ & $n$ & $\begin{array}{c}\mu \\
(\mathbf{M P a})\end{array}$ & $\begin{array}{c}\sigma \\
(\mathbf{M P a})\end{array}$ & $\delta$ & $\beta$ & $n$ \\
\hline C20 & 23,7347 & 0,9861 & $4,15 \%$ & 10,5015 & 60 & - & - & - & - & 0 \\
\hline $\mathrm{C} 25$ & 29,2942 & 0,5332 & $1,82 \%$ & 23,9717 & 135 & 27,6432 & $10^{-14}$ & $10^{-16}$ & $10^{3}$ & 32 \\
\hline C30 & 30,6177 & 0,2137 & $0,7 \%$ & 32,4949 & 86 & 35,4251 & 2,1242 & $6 \%$ & 7,27 & 249 \\
\hline $\begin{array}{c}\text { Amostras } \\
\text { totais }\end{array}$ & 40,737 & 3,7532 & $9,21 \%$ & 4,7359 & 281 & - & - & - & - & \\
\hline
\end{tabular}




\section{Contribuições analíticas do projeto de revisão da NBR 7190}

Desde 2002 a ABNT atua em um projeto de revisão elaborado pela Comissão de Estudo de Estruturas de Madeiras, ABNT/CE-02:126.10, do Comitê Brasileiro da Construção Civil, ABNT/CB-02.

As classes de resistência das madeiras têm por objetivo o emprego de madeiras com propriedades padronizadas, orientando a escolha do material para elaboração de projetos estruturais. Nesta revisão, há o enquadramento das espécies de madeira nas classes de resistência especificadas somente para o caso das dicotiledôneas, também chamadas de folhosas, para uma condição padrão. Foram aqui indicadas as classes de resistência de espécies de florestas nativas definidas em ensaios de corpos de prova isentos de defeitos, D20, D30, D40, D50 e D60, que representam os resultados de resistências à compressão paralela às fibras, características em $\mathrm{MPa}(20,30,40,50$ e $60 \mathrm{MPa}$ respectivamente), conforme a Tabela 6, extraída do projeto de revisão da NBR 7190.

Nesse caso, a proposta de revisão da NBR 7190 não enquadra uma divisão das classes, definidas em ensaios de corpos de prova isentos de defeitos, para coníferas, pois considera que essas espécies não são de florestas nativas. Ressalta-se que esse é um ponto que merece atenção porque inúmeras espécies de madeiras coníferas já foram incorporadas ao contexto brasileiro, e conforme normatização de 1997 já têm ampla e costumeira utilização por projetistas e construtores em diversos rincões do Brasil.

Aplicando a proposta de análise probabilística desenvolvida neste trabalho no contexto de revisão da NBR 7190, utilizando-se o $C V$ sugerido pela norma e o calculado a partir das amostras, é possível constatar a quantidade de exemplares que existiam no Anexo E da versão de 1997 (que não será incorporado à nova norma) e que podem ser enquadrados nas classes propostas, segundo o $C V$ proposto pela norma e segundo o $C V$ proposto pela análise das amostras, conforme a Tabela 7.

A inclusão da classe D50 permite a absorção de espécies que, conforme o ajuste nos dados, foram excluídas da classe D60, contudo ainda 10 exemplares não atingem a classe D20, sendo, desse modo, interessante a inclusão de uma classe inferior.

Salienta-se novamente que a proposta de revisão não considera as amostras ensaiadas de coníferas na versão de 1997 da norma, pois considera que não existem coníferas tropicais no país, não levando em conta as contribuições que até então vigoram na versão de 1997 da norma.

Ao desconsiderar as coníferas, a norma exclui a utilização de madeiras de espécies importantes e comumente utilizadas, tais como o Pinus taeda e o Pinus elliottii, plantados no Brasil e utilizados em peças de madeira laminada colada (MLC) e cruzada, a Cross Laminated Timber (CLT).

Tabela 6 - Classes de resistência de espécies de florestas nativas definidas em ensaios de corpos de prova isentos de defeitos

\begin{tabular}{c|c|c|c|c}
\hline Classes & $\begin{array}{c}f_{c 0 k} \\
\mathbf{M P a}\end{array}$ & $\begin{array}{c}\boldsymbol{f}_{\boldsymbol{v} \boldsymbol{0}, \boldsymbol{k}} \\
\mathbf{M P a}\end{array}$ & $\begin{array}{c}\boldsymbol{E}_{\boldsymbol{c} \boldsymbol{0}, \boldsymbol{m}} \\
\mathbf{M P a}\end{array}$ & $\begin{array}{c}\rho_{a p a r e n t e} \\
\mathbf{k g} / \mathbf{m}^{\mathbf{3}}\end{array}$ \\
\hline D20 & 20 & 4 & 9.500 & 650 \\
D30 & 30 & 5 & 14.500 & 800 \\
D40 & 40 & 6 & 19.500 & 950 \\
D50 & 50 & 7 & 22.000 & 970 \\
D60 & 60 & 8 & 24.500 & 1.000 \\
\hline
\end{tabular}

Fonte: extraída do Projeto de Revisão da NBR 7190 (ABNT, 2020).

Nota: 1. Valores obtidos de acordo com o Projeto 002:126.010-001-2; e 2. Valores referentes ao teor de umidade igual a $12 \%$.

Tabela 7 - Número de amostras em cada classe homogênea de resistência para a revisão da norma

\begin{tabular}{c|c|c} 
& Norma & Amostras \\
\hline D20 & 153 exemplares & 388 exemplares \\
D30 & 480 exemplares & 448 exemplares \\
D40 & 252 exemplares & 239 exemplares \\
D50 & 200 exemplares & 44 exemplares \\
D60 & 44 exemplares & 0 exemplares \\
\hline
\end{tabular}


Tabela 8 - Classes de resistência definidas em ensaios de peças estruturais

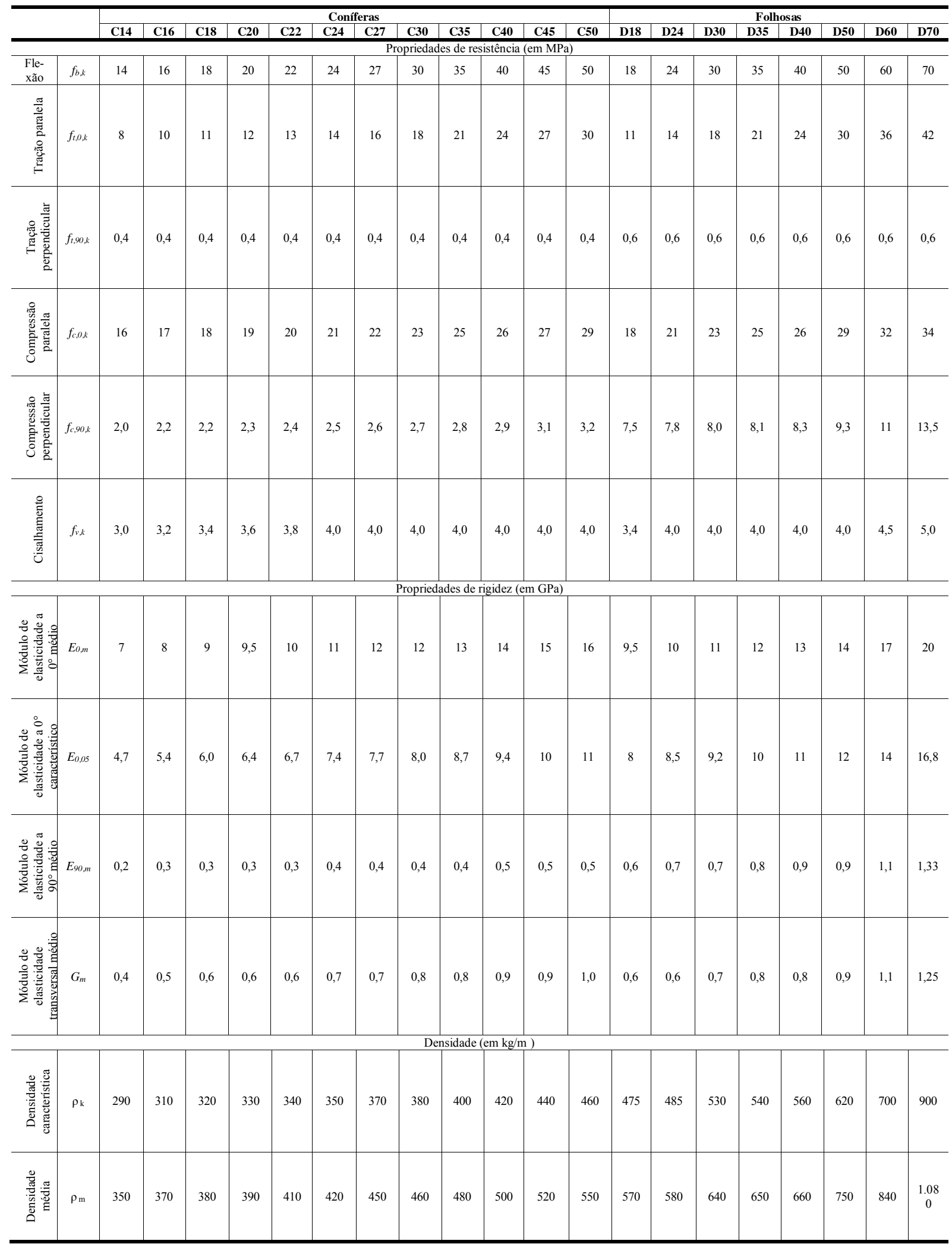

Fonte: extraída do Projeto de Revisão da NBR 7190 (ABNT, 2020).

Nota: 1. Valores obtidos conforme o Projeto 002:126.10-001-3; e 2. Valores referentes ao teor de umidade igual a $12 \%$. 
Observa-se também que no projeto de revisão da NBR 7190 (ABNT, 1997) algumas abordagens que estavam omissas na versão anterior foram introduzidas, tal como a inclusão da classe D50. Contudo, a remoção dos anexos, tal como o Anexo E, dificulta a alocação das classes com as espécies, o que do ponto de vista prático pode dificultar a escolha e a seleção de opções em projeto de estruturas de madeira.

Outro ponto que chama a atenção é a possível inclusão de uma tabela que especifica as classes de resistência a partir de ensaios de peças estruturais. Essa tabela, inspirada na UNI EN 338 (EUROPEAN..., 2009), norma europeia "Structural timber - Strength classes", especifica as classes de resistência para dicotiledôneas (folhosas) e coníferas. Para as coníferas são adotadas as classes C14, C16, C18, C20, C22, C24, C27, C30, C35, C40, C45 e C50, e para as dicotiledôneas, as classes D18, D24, D30, D35, D40, D50, D60 e D70, conforme a Tabela 8, extraída do projeto de revisão da norma 7190, adaptada da UM 338 (European Standard Of Structural Timber - Strenght Classes).

Contudo, esse método de classes da norma europeia é baseado na resistência à flexão, diferente das classes propostas comumente no Brasil, dadas por resistência à compressão paralela às fibras. Essa padronização com base em critérios diferentes pode gerar entendimentos dúbios aos projetistas de estruturas de madeira, ao apresentar classes que seguem a mesma designação, mas que, na prática, têm resistências diferentes. Por exemplo, uma peça de madeira classe D30, segundo as classes adotadas comumente no Brasil, teria $30 \mathrm{MPa}$ de resistência à compressão, contudo para os padrões adaptados da norma europeia essa peça teria $30 \mathrm{MPa}$ de resistência à flexão e, de fato, teria $23 \mathrm{MPa}^{1}$ de resistência à compressão paralela às fibras.

Tal procedimento de simples ajuste de nomenclatura pode representar na prática a utilização de peças com resistências inferiores, o que pode oferecer riscos ao projeto. Também gera preocupação no projeto de revisão da norma, que sugere que, caso não existam resultados para as tensões de resistência à flexão, o valor da tensão resistente de cálculo à flexão deve ser o mesmo valor da resistência de cálculo à compressão paralela às fibras.

\section{Conclusão}

A abordagem proposta neste trabalho indica que os dados propostos no Anexo E da NBR 7190 (ABNT, 1997) podem não ser normalmente distribuídos, acarretando distorções na obtenção das resistências características à compressão paralela às fibras na madeira. Ainda, a uniformização de um único coeficiente de variação entre coníferas e dicotiledôneas não foi ratificada na análise dos dados, assim como a homogeneização de classes também gera diferentes coeficientes de variação.

A transformação de valores de resistência média em valores de resistências características precisa ser recalibrada a partir de um coeficiente de variação específico para cada categoria, dicotiledônea ou conífera. Assumir um único $C V$ para ambos não reflete a distribuição de amostras considerada pela norma.

Conclui-se que, com o enfoque probabilístico aplicado na distribuição de frequência de resistência à compressão paralela às fibras oriunda de amostras da NBR 7190 (ABNT, 1997), foi possível calcular o índice de confiabilidade que a norma garante aos projetos de estruturas de madeira, apontando que a característica dos dados altera o índice de confiabilidade para coníferas e dicotiledôneas.

Com vistas ao impactos do projeto de revisão da norma, verificando o comportamento da inclusão de mais uma classe de resistência e a supressão das propriedades apresentadas por espécie, observa-se ainda que, a despeito da proposta de revisão da norma, a supressão do Anexo E faz com que a nova norma não traga em seu escopo informações sobre as propriedades físicas e mecânicas das espécies de madeiras de uma forma mais ampliada e abrangente, tendo como consequência uma lacuna técnica aos interessados na utilização da madeira em estruturas e construções em geral.

Considera-se de fundamental importância, para trabalhos futuros, uma análise com dados primários obtidos de forma sistêmica em abordagens experimentais para ratificar a proposta contida neste trabalho, verificando-se os resultados para diferentes solicitações, ou seja, tração, cisalhamento e flexão.

\footnotetext{
${ }^{1}$ A norma UNI EN 338 (EUROPEAN..., 2009) admite que a $\boldsymbol{f}_{\boldsymbol{c}, \boldsymbol{0} \boldsymbol{k}}=\mathbf{5} \times \boldsymbol{f}_{\boldsymbol{m}}{ }^{\mathbf{0 , 4 5}}$.
} 


\section{Referências}

ADOLFS, D. V. Análise de confiabilidade de peças de madeira fletidas dimensionadas Segundo a NBR 7190/97. São Carlos, 2011. 95 f. Dissertação (Mestrado em Engenharia Civil) - Programa de Pós-Graduação em Engenharias de Estruturas, Universidade de São Paulo, São Carlos, 2011.

ANG, A. H-S.; TANG, W. H. Probability concepts in engineering planning and design: basic principles. New York: John Wiley \& Sons, 1975.

ASSOCIAÇÃO BRASILEIRA DE NORMAS TÉCNICAS. NBR 7190: projeto de estrutura de madeira. Rio de Janeiro, 1997.

ASSOCIAÇÃO BRASILEIRA DE NORMAS TÉCNICAS. NBR 7190: projeto de estrutura de madeira. ABNT/CB-02 - 2º Projeto de revisão da ABNT NBR 7190. Rio de Janeiro, 2020.

BADIMUENA, B. L. Avaliação da confiabilidade de estruturas existentes: influência da resistência à compressão do concreto. Belo Horizonte, 2017. Dissertação (Mestrado em Engenharia Civil) - Universidade Federal de Minas Gerais, Belo Horizonte, 2017.

BEEBY, A. W. Partial safety factors: an overview. The Structural Engineer, v. 72, n. 2, jan. 1994.

CHEUNG, A. B. et al. Confiabilidade estrutural de uma ponte protendida de madeira considerando o tráfego real. Ambiente Construído, Porto Alegre, v. 17, n. 2, p. 221-232, abr./jun. 2017.

CHEUNG, A.; PINTO, M. E.; CALIL JUNIOR, C. Confiabilidade estrutural de vigas de madeiras submetidas à flexão em condições normais e em situação de incêndio. Madeira: Arquitetura e Engenharia, v. 12, n. 29, 2011.

COMITÉ EUROPÉEN DE NORMALIZATION. Eurocode 5: design of timber structure: part 1-1: general: common rules and rules for buildings. Brussels, 2004.

CORNELL, C. A. A probability-based structural code. ACI-Journal, v. 66, p. 974-985, 1969.

COSTA, C. N. Confiabilidade estrutural: sobre os estimadores de resistência à compressão do concreto. São Paulo, 2017. 145 f. Monografia (Curso de Especialização em Gestão de Projetos de Sistemas Estruturais) - Programa de Educação Continuada, Escola Politécnica, Universidade de São Paulo, 2017.

DEVORE, J. L. Probabilidade e estatística: para engenharia e ciências. 6. ed. São Paulo: Cengage Learning, 2006.

DITLEVSEN, O.; MADSEN, H. O. Structural reliability methods. New York: Wiley, 1996.

ELLINGWOOD, B. R. LRFD: implementing structural reliability in professional practice. Engineering Structures, n. 22, p. 106-115, 2000.

EUROPEAN STANTADARD. UNI EN 338: structural timber: strength classes. 2009. Disponível em: http://www.dmh.or.kr/forceboard/data/board/size02/file_in_body/1/UNI_EN_338.pdf. Acesso em: 05 jan. 2021.

FREITAS, A. R. Probabilistic approach in the design of wood structures in Brazil based on the variability of 23 species. São Paulo, 1978. 76 f. Instituto de Pesquisas Tecnológicas (IPT), Divisão de Madeiras, 1978. Boletim IPT - publicação 1198.

FUSCO, P. B. Fundamentos estatísticos da segurança das estruturas. São Paulo: Edusp, 1976.

FUSCO, P. B. Uma proposta de normalização das resistências da madeira estrutural. In: ENCONTRO REGIONAL DE MADEIRAS E ESTRUTURA DE MADEIRA, 1., São Paulo, 1993. Anais [...] São Paulo, 1993.

GALAMBOS, T. V. et al. Probability based load criteria: assessment of current design practice. Journal of the Structural Division, v. 108, n. ST5, p. 959-977, May 1982.

GREEN, D. W.; KRETSCHMANN, D. E. Stress class system: an idea whose time has come? US Department of Agriculture. Forest Services. Forest Products Laboratory, 1990. Research Paper, n. 500.

HASOFER, A. M.; LIND, N. An exact and invariant first-order reliability format. Journal of Engineering Mechanics, v. 100, n. EM1, p. 111-121, 1974.

LIN, T. S.; COROTIS, R. B. Limit state reliabilities of structural systems. American Society of Civil Engineer, v. 111, n. 6, p. 53-56,1984. 
MACGREGOR, J. G. Safety and limit states design for reinforced concrete. Canadian Journal of Civil Engineering, v. 3, p. 484-513, 1976.

MEYER, P. L. Probabilidade: aplicações à estatística. 2. ed. 16. reimp. Rio de Janeiro: LTC, 2015.

MITRE, M. P. Metodologia para inspeção e diagnóstico de pontes e viadutos de concreto. São Paulo, 2005. 148 f. Dissertação (Mestrado em Engenharia Civil) - Escola Politécnica, Universidade de São Paulo, São Paulo, 2005.

NOVA, S. J. S. Avaliação da segurança de pontes em concreto protendido sob solicitações normais com base na teoria da confiabilidade. Campinas, 2017. 124 f. Dissertação (Mestrado em Projeto de Estruturas) - Faculdade de Engenharia Civil, Arquitetura e Urbanismo, Universidade Estadual de Campinas, Campinas, 2017.

RACKWITZ, R.; FIESSLER, B. Structural reliability under combined random load sequences computers and structures. Computers and Structures, v. 9, n. 5, p. 489-494, 1978.

ROCCO LAHR, F. A. Considerações a respeito da variabilidade de propriedades de resistência e de elasticidade da madeira. São Carlos, 1990. 104 f. Tese (Livre Docência) - Escola de Engenharia de São Carlos, Universidade de São Paulo, São Carlos, 1990.

SALES, A. Sistema de classes de resistência para dicotiledôneas: revisão da NBR 7190/97. Revista Madeira: Arquitetura e Engenharia, v.13, n. 9, 2004.

SALES, A.; LAHR, F. A. R. Proposição de classes de resistência para madeira. São Paulo: Departamento de Engenharia de Construção Civil da Universidade de São Paulo, 1996. Boletim Técnico, n. 166.

SANTIAGO, W. G. Calibração baseada em confiabilidade dos coeficientes parciais de segurança das principais normas brasileiras de projeto estrutural. São Carlos, 2019. $181 \mathrm{f}$. Tese (Doutorado em Ciências) - Escola de Engenharia de São Carlos, Universidade de São Paulo, São Carlos, 2019.

SANTOS, V. M. P. Análise de confiabilidade em modelos de bielas e tirantes. Goiânia, 2014. 133 f. Dissertação (Mestrado em Engenharia Civil) - Programa de Pós-Graduação em Geotecnia, Estruturas e Construção Civil, Universidade Federal de Goiás, Goiânia, 2014.

SIMONETTI, M. J. et al. A importância da engenharia da confiabilidade e os conceitos básicos de distribuição de Weibull. Revista Sapere, Tatuí, v. 1, n. 1, jul./dez. 2009.

TRAMONTINI, P. M. Estudo de confiabilidade para seções de concreto armado submetidas a diversos tipos de esforços. Rio de Janeiro, 2016. 98 f. Dissertação (Mestrado em Projeto de Estruturas) - Programa de Projeto de Estrutura, Universidade Federal do Rio de Janeiro, Rio de Janeiro, 2016.

VIALI, L. Teste de hipóteses não paramétricas. Porto Alegre: Departamento de Estatística da Universidade Federal do Rio Grande do Sul, 2008.

VILELA, R.; MASCIA, N. T.; SANTOS, L. F. Structural reliability analysis of cross laminated timber plates subjected to bending. In: SOCIETY OF WOOD SCIENCE AND TECHNOLOGY INTERNATIONAL CONVENTION, Portoroz, 2020. Proceedings [...] Portoroz, 2020.

VROUWENVELDER, T. The JCSS probabilistic model code. Structural Safety, v. 19, n. 3, p. 245-251, 1997.

WALPOLE, R. E. et al. Probabilidade e estatística: para engenharia e ciências. 8. ed. São Paulo: Pearson, 2015. 


\section{Rafael Barreto Castelo da Cruz}

Departamento de Estruturas | Universidade Estadual de Campinas | Av. Albert Einstein 951, $1^{\circ}$ Andar, Sala 12, Cidade Universitária | CEP 13083-852 | Campinas - SP - Brasil | E-mail: rbcruz@pucsp.br

\section{Luciano Ferreira dos Santos}

Departamento de Estruturas | Universidade Estadual de Campinas | E-mail: 173fsantos@gmail.com

\section{Nilson Tadeu Mascia}

Departamento de Estruturas | Universidade Estadual de Campinas | Tel.: (19) 3521-2318 | E-mail: nilson@fec.unicamp.br

Maria Cecilia Amorim Teixeira da Silva

Departamento de Estruturas | Universidade Estadual de Campinas | Tel.: (19) 3521-2414 | E-mail: cecilia@fec.unicamp.br

Ambiente Construído

Revista da Associação Nacional de Tecnologia do Ambiente Construído

Av. Osvaldo Aranha, $99-3^{\circ}$ andar, Centro

Porto Alegre - RS - Brasil

CEP $90035-190$

Telefone: +55 (51) 3308-4084

Fax: +55 (51) 3308-4054

www.seer.ufrgs.br/ambienteconstruido

E-mail: ambienteconstruido@ufrgs.br 